\title{
Spatial Distribution of Crime in Bangladesh: An Analysis
}

\author{
Factors that Caused Decline Crime Rates in Developed Western \\ Countries (1990-2008)
}

\section{Md. Bashir Uddin KHAN ${ }^{1,2}\left(\mathbb{0}\right.$, Md. Ishtiaq Ahmed TALUKDER ${ }^{3,4}$ ()}

${ }^{1} \mathrm{PhD}$ Candidate, Department of Sociology, School of Sociology and Political Science, Shanghai University, Shanghai, China

${ }^{2}$ Associate Professor, Department of Criminology and Police Science, Mawlana Bhashani Science and Technology University, Santosh, Tangail, Bangladesh

${ }^{3} \mathrm{PhD}$ Candidate, Department of Security Strategies and Management, Institute of Security Sciences, Turkish National Police Academy, Ankara, Turkey

${ }^{4}$ Associate Professor, Department of Criminology and Police Science, Mawlana Bhashani Science and Technology University, Santosh, Tangail, Bangladesh

ORCID: B.U.K. 0000-0003-0652-158X; I.A.T. 0000-0001-6702-5446

\section{ABSTRACT}

Crime mapping has become popular as a way of analysing the spatial distribution of crime, and its use enables effective crime prevention strategies to be employed based on the analysis of hotspots. However, in Bangladesh crime mapping using Geographic Information System (GIS) is still in its infancy. This paper intends to focus on the spatial distribution of crime throughout the major administrative divisions of Bangladesh and to explore how it varies according to region. Its objective is to fill the existing knowledge gap in terms of the spatial distribution of crime in Bangladesh with the help of GIS software. All associated issues behind any crime patterns in different regions have been analysed here using references from established research. This study also illustrates the trend analysis of crime in the last three years, from 2016 to 2018 , to understand the patterns of crime distribution as per present administrative divisions. It also focuses on the relative frequency of incidents of crime in all the regions of Bangladesh. Additionally, this study indicates that areas with big cities (Dhaka and Chattogram) are more prone to harbouring a greater number of offenders than other areas. As an initial study using GIS-based computerised crime mapping in Bangladesh, this research may have an important role in showing division wise crime distribution.

Keywords: Crime mapping, Division, Spatial Distribution, Predictive Policing, Violent Crimes, Property Crimes

Submitted: 02.05.2021 • Revision Requested: 25.08.2021 • Last Revision Received: 28.08.2021 • Accepted: 16.09 .2021 • Published Online: 25.10 .2021

Corresponding author: Md. Ishtiaq Ahmed Talukder, E-mail: i.a.talukder@hotmail.com

Citation: Khan, MBU, Talukder, MIA, 'Spatial Distribution of Crime in Bangladesh: An Analysis' (2021) 9(2) Ceza Hukuku ve Kriminoloji Dergisi-Journal of Penal Law and Criminology, 479. https://doi.org/10.26650/JPLC2021-931625 


\section{Introduction}

Crime mapping is very crucial for understanding the spatial distribution of crime in particular administrative divisions or jurisdictions. Thematic maps of various forms such as line data, point data, polygon data, and statistical data can indicate the actual patterns of crime and help the researchers and crime investigators find out probable causes and solutions to prevent a myriad of crimes in the vicinity. Although the history of crime mapping using GIS software has had much success in developed countries over a period of some decades, for Bangladesh with a population of 161 million, GIS in crime analysis is still in its infancy. This limited use of GIS in Bangladesh is associated chiefly with land management and geographical research. Therefore, the use of GIS in dealing with crime data has, until now, been very limited. One significant factor which limits the analysis of crime distribution with the help of GIS in Bangladesh is the unavailability of and inaccessibility to primary crime data.

Bangladesh is a country in South Asia situated between 20.86382 to 26.33338 latitude and 88.15638 to 92.30153 longitude (Bangladesh Latitude and Longitude Map, n.d.). The country shares border with India to the east, west, and north. In the southeast it borders Myanmar with the Bay of Bengal to the south (ibid.). According to the estimates, the current population of Bangladesh is 161,356,039 as of 2018 ("Population, totalBangladesh," n.d.). It is a developing country where the frequency of crime is very high because of different socio-economic and geographic factors (Faruk \& Talukder, 2010; Khan, Alam, \& Faruk, 2014; Khan \& Kamruzzaman, 2010; Khan \& Shathi, 2018; Tang \& Khan, 2018). The use of crime mapping can help police personnel, investigators, and other professionals to understand various factors associated with those crimes. Thus, it can help formulate effective policy and policing strategies to reduce the frequency of crime by understanding crime distributions and various other underlying issues. Police data available in various formal sources can match spatial data to conclude the causes, factors, and probable solutions of crime as well as helping with other factors such as police personnel recruitment and priority determination.

Mapping can be a critical part of policing activities to focus on appropriate responses for fighting crime (Fitterer, Nelson, \& Nathoo, 2015; Gottschalk \& Ørn, 2012; Moncada, 2010; Pope \& Song, 2015; Xiong, 2016). Thus, building smart cities without such a mapping procedure in the context of crime control is nearly impossible. Because of the comprehensive nature of crime mapping, it can help criminal justice professionals and criminologists to understand crime from a geographical aspect and address the 
problem efficiently through better allocation of resources (Bowers \& Johnson, 2014; Leclerc, Chiu, Cale, \& Cook, 2016; Leong \& Chan, 2013). The objective of this study is to find out the associated factors of crimes and their geographic distribution. In this way, it can help criminal justice professionals and other stakeholders to understand the distribution of crimes and their relative importance.

Social scientists' growing interest in geography and crime has made crime mapping very important (Bernasco \& Elffers, 2010). In Bangladesh, little research has been conducted to understand crime through thematic mapping (Saadi, Rahman, and Talukder, 2008). However, a number of studies are available in other countries. In this context, this study intends to narrow the gap of a countrywide crime analysis through mapping. While many prior studies in different countries have used Ordinary Least Squares (OLS) regression or geographically weighted regression (Boivin, 2018; Wang, Lee, \& Williams, 2019; Zhang \& Song, 2014), due to data limitations our focus will be concentrated on understanding the geographic variation of crime incidents among all the administrative divisions of Bangladesh to reveal the relative frequency of crimes and their probable predicting factors.

In the present context, viewing map data is an easier way to understand the necessity of intervention in a particular region or area. Computer-based crime mapping has received immense popularity nowadays because of its flexibility with data, statistics, and geographic contents. Geographic information is much more user-friendly now, and users can use different tools and techniques complying with organisational requirements with greater flexibility. For this reason, the use of a thematic map can be an excellent option for crime analysts (Harries, 1999). The thematic map works as a complete package where anybody can select a topic and choose any possible means to convert data into a comprehensible map in order to communicate to the target population efficiently and effectively. Thematic maps can be both quantitative and qualitative. With the help of these maps, crime mapping has started to play a significant role in effective crime management by adopting scientific crime prevention methods in an established theoretical framework. For the last quarter-century, crime mapping has increasingly become an integral part of policing activities worldwide.

Clarifying where different types of crime and other incidents occur is one of the many important functions of crime analysis. Due to the unique nature of the sophisticated software and the type of data used sometimes, the difference between crime analysis and crime mapping may be difficult. Crime mapping is better considered as the sub- 
discipline of crime analysis. It provides maps that help to communicate the results with all stakeholders.

Nowadays, a significant number of alternatives are also available in crime mapping practice (Shekhar, Xiong, \& Zhou, 2017). Whether the problem is tactical, strategic, or administrative, any data containing location information can be displayed and analysed using geographic information system (GIS) technology developed by Environmental Systems Research Institute (ESRI) of California. Place-based policing is considered to help decrease crimes. The theory is that those specific areas have properties that make them more attractive to the probable offenders for committing specific crimes. For example, auto theft may happen more frequently in those areas where cars are available outside of the apartment complex. These complexes can be hot spots for auto-related crimes. However, previous studies discovered that the existing methods of predicting and mapping the future locations of crime are intrinsically retrospective. We need to analyse the prospective methods from a careful selection of methods.

Some researchers have proposed certain specialised models to analyse a variety of crimes. For homicide analysis, a model named "Spatial Configuration of Homicide Crime" (SCHC) was proposed combining factors like the offender's residence, the victim's residence, the murder location, and the disposal location. Based on these locational components, individual crime data can be analysed (Kim, Chun, \& Gould, 2013). For this, individual data referring to this information are required. For analysing burglary, larceny, and auto theft, Global Moran autocorrelation (Moran scatterplots) is an excellent way to analyse incidents (Sim \& Miller, 2016). For analysing rape incidents, spatial scan statistic has been used in many studies. This technique is generally considered a good geographic surveillance tool (Amin, Nabors, Nelson, Saqlain, \& Kulldorff, 2015). Some researchers have used spatial data analysis (ESDA) to understand different micro and macro territorial features of criminal incidence (Cracolici \& Uberti, 2009). Other researchers have explained crimes by analysing their spatio-temporal features with 3D and 4D modelling (Wolff \& Asche, 2009). Still more scholars are interested in working on the spatial-temporal analysis of crime patterns for different days of the week (Andresen \& Malleson, 2015).

A significant amount of information and a great number of subsidiary parameters are required for the mapmaking process in crime analysis. When maps are produced based on vast amounts of data and numerous parameters, the task of preventive policing by 
crime forecasting becomes easier. Predicting policing may be a great outcome of such a mapping process with large databases. The master crime incident layers and standard map layers provide the capacity to produce such maps quickly and accurately. A staple of every crime analysis unit is an $\mathrm{SQL}^{1}$ (Structured Query Language) compatible database. Databases are essential for gathering, storing and manipulating data that is often retrieved or exported from various other databases, such as an $\mathrm{RMS}^{2}$ (Record Management Systems), CAD ${ }^{3}$ (Computer-Aided Design) system or others (Harkins \& Reid, 2002; Leitner, 2013; Maltz, Gordon, \& Friedman, 1991).

This study intends to conduct a spatial analysis based on available regional data. However, the available crime data are not merely local here; instead, they are regional and aggregated. This study has yielded some important findings as to the pioneering work of crime mapping through GIS in the criminal justice sector of Bangladesh.

\section{Objectives of the Study}

The focus of the study is to know how crime patterns of different divisions are spatially distributed in Bangladesh. Additionally, this research analyses the differences in crime patterns in different years. The current research explains some probable factors as well, which are primarily liable behind the commission of specific crimes at specific places in a significant figure. Based on the research objectives, the following research questions were formulated for the present study-

What is the nature of property-related and violent crimes in Bangladesh from a comparative perspective?

How are the crimes generally clustered in accordance with the divisions?

Why do the patterns of crimes differ according to the different geographic locations in Bangladesh (Comparative analysis)?

\section{Method}

This study aims at understanding crime distribution following geographical locations. We used different spatial data and shapefiles from different online sources. Two websites

1 This SQL is a computer language that helps to retrieve and manage data in a database having relational database.

2 RMS data management system is an agency-wide system that helps any agency to story, retrieve, manupulate, view and archive all the data.

3 CAD system generally refes to such file that store information in course of matching, viewing and and assembling compterized full records. 
(www.diva-gis.org/gdata and www.gadm.org) were used to collect shapefiles of base maps for this study. We collected crime statistics for this study from the official website of the Bangladesh police (www.police.gov.bd/en/crime_statistic) during the study period (2016-2018). We then merged and reclassified the areas according to the administrative police divisions. At the time of the study there were eight civil ranges and one railway range in Bangladesh. As per the data available, we selected these eight ranges to show the distribution of crimes and omit the present study's railway range. Although these ranges are not equal in size and population, significant findings can be extracted from the study about the relative crime frequency.

We used crime data and other demographic data to determine the relationship of these with the shapefiles for different divisions of Bangladesh. This study combines both qualitative and quantitative approaches to the analysis of data. Our research has also generated information on crime patterns, comparison among the crime data, and the determination of an effective strategy to solve ongoing problems and address the crimes appropriately based on spatial analysis. We used different tables, graphs, maps, and other pictorial diagrams to analyse and express the main issues. We generously used various secondary sources like books, edited books, newspapers, government and institutional reports, websites, journal articles, and other resources to compare the data and reach a conclusion (Table 1).

Table 1. Summary of research methodology

\begin{tabular}{|l|l|}
\hline Research Area & Eight civil ranges of Bangladesh \\
\hline Research philosophy & Positivist \\
\hline Research Paradigm & Interpretive \\
\hline Research approach & Inductive \\
\hline Time horizon & Longitudinal \\
\hline $\begin{array}{l}\text { Data types/ } \\
\text { Sources of data }\end{array}$ & $\begin{array}{l}\text { Secondary: Police statistics of Bangladesh (from the official website } \\
\text { of Bangladesh Police at different time points), Bangladesh Bureau } \\
\text { of Statistics, websites, books, journals, government publications, } \\
\text { newspaper etc. }\end{array}$ \\
\hline
\end{tabular}

\section{Result}

The whole territory of Bangladesh is divided into eight different administrative divisions. For the police, these jurisdictions are generally termed as police ranges. Along with these eight police ranges, there is one division dedicated to railway (termed as the railway range). The same administrative divisions for the civil administrations are also subject to the police jurisdictions (for policing, these are termed as ranges). Each of these ranges is composed 
of some districts. The names of all these ranges are Dhaka, Chattogram, Rajshahi, Khulna, Barisal, Sylhet, Rangpur, and Mymensingh. Apart from these, there are six metropolitan police departments in Bangladesh in the six largest metropolitan cities. Beyond these six metropolitan areas, all the territories of the country are operated under the supervision of any of these ranges. All district police (there are currently 64 districts in Bangladesh) work under the supervision of their respective ranges. It should be mentioned that all districts are not necessarily equal in terms of area or population. The purpose of establishing these ranges is to make the management process more decentralised and effective under the coordination of local police headquarters. This research includes all ranges differently and amalgamates the metropolitan police statistics into the respective ranges (similar to administrative divisions). Thus, the result of this paper includes crime data based on eight administrative divisions, not only based on the police range but also the respective metropolitan police of each division. The distribution is shown both according to the number of total crimes and the crime rates. The rate is calculated per million with the respective total population of a particular division. So, the equation for the calculation of the rate is

$$
\text { The rate of a particular crime }=\frac{\text { Total umber of that crime in a given year }}{\text { total population of the division }} \times 1000,000
$$

The following table indicates the current number of districts under eight divisions of Bangladesh (Table 2). The data were found in the Statistical Pocket Book Bangladesh 2018 and the National Web Portal of Bangladesh. The total population data in all divisions were taken from the latest national census of Bangladesh (Population and housing census of 2011). Additionally, the map (Figure 1) displays all the divisions of Bangladesh with their respective districts inside.

Table 2. Number of Districts for Each Police Range

\begin{tabular}{|l|c|c|c|}
\hline $\begin{array}{l}\text { Divisions (Ranges including } \\
\text { Respective Metropolitan Police) }\end{array}$ & $\begin{array}{c}\text { Number of } \\
\text { Districts }\end{array}$ & $\begin{array}{c}\text { Total } \\
\text { Population }\end{array}$ & Metropolitan Police Included \\
\hline Dhaka & 13 & $36,433,505$ & Dhaka Metropolitan Police \\
\hline Chattogram & 11 & $28,423,019$ & Chattogram Metropolitan Police \\
\hline Rajshahi & 8 & $18,484,858$ & Rajshahi Metropolitan Police \\
\hline Khulna & 10 & $15,687,759$ & Khulna Metropolitan Police \\
\hline Barisal & 6 & $8,325,666$ & Barisal Metropolitan Police \\
\hline Sylhet & 4 & $9,910,219$ & Sylhet Metropolitan Police \\
\hline Rangpur & 8 & $15,787,758$ & ---- \\
\hline Mymensingh & 4 & $10,990,913$ & ----- \\
\hline Total & 64 & $144,043,697$ & 06 \\
\hline
\end{tabular}

Data Source: BBS, Bangladesh Police Website and National Web Portal of Bangladesh.

(Table developed by authors) 
Figure 1. All Administrative Divisions of Bangladesh (Source: Developed by Authors)

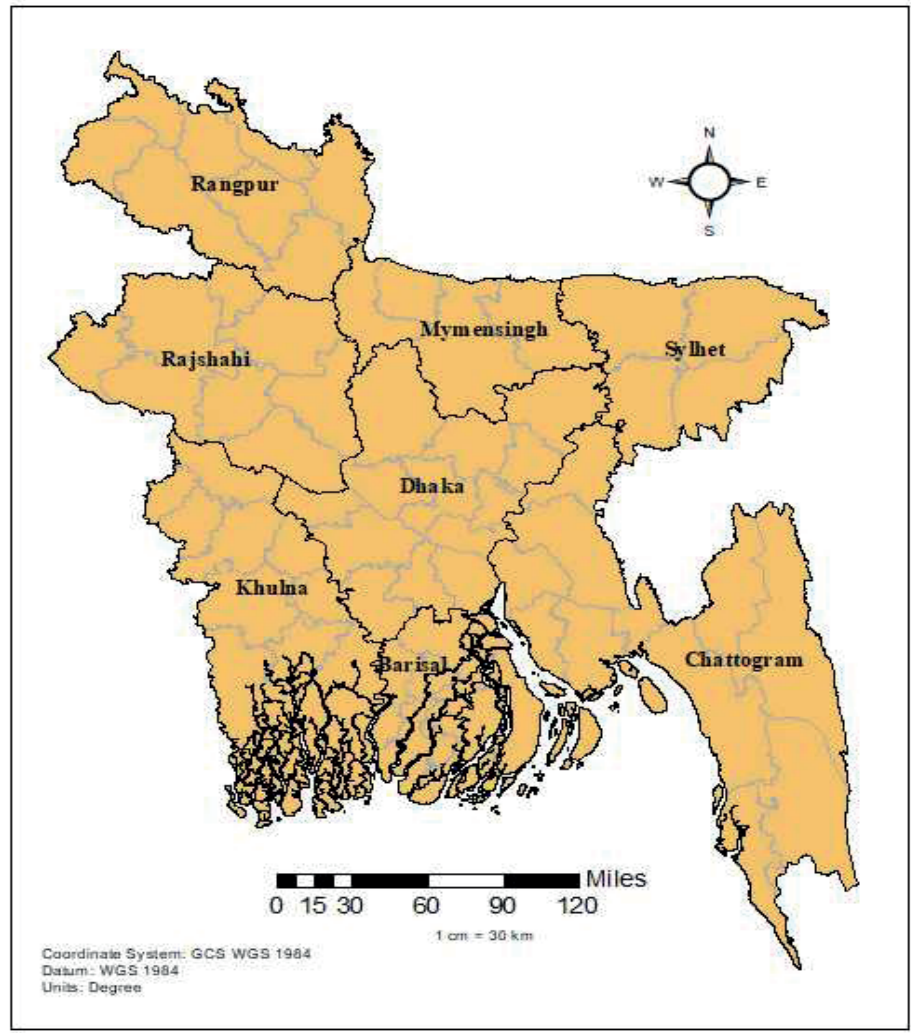

\section{Spatial Distribution of Different Crimes According to Police Data}

It is a common assumption of criminology that crimes of any given country are not always recorded. There are some crimes that may be recorded erroneously, or some cases are not recorded at all because of people's lack of confidence in the policing system or the perception that the incidents are trivial or trifling. Thus, some crimes are reported but not recorded and some crimes are recorded but actually not committed (Bohm \& Haley, 2017). Bohm and Haley (2002) termed the difference between the actual occurrence of crimes and the reported crimes as the "dark figure of crime". In crime records, there will always be some grey areas that are difficult to overcome. However, this study has considered the recorded and published police data as authentic and used these official crime records for the spatial distribution. For the present analysis, all the selected crimes are categorised as property crimes and violent crimes. 


\section{Property Related Offences of Bangladesh}

Generally, crimes which are committed against the rights or the property of persons (the main target is the property), and not against the persons predominantly, are considered property-related crimes. For this study, four crimes have been selected as property crimes: theft, burglary, dacoity, and robbery. Although some force may be reported to be used in robbery and dacoity, the main target of such crimes is to gain the property in an illegal way. The analysis of the present study goes as follows.

\section{Theft and Burglary}

From the comparative statistical maps of all divisions, it becomes clear that theft and burglary are the most frequent property-related crimes in Bangladesh (Figure 2 and Figure 3). From the police statistics, it is evident that theft and burglary are the most common forms of property crimes registered in the police stations. The number of thefts in police reports shows that most of the incidents of dacoity are distributed in Dhaka, Chattogram and Sylhet. Considering the rate of theft (calculating the crimes based on per million people), Dhaka and Sylhet remain at the top among all the divisions. Thus, calculating the total and calculating the rates portray different pictures about the distribution of theft among different divisions (Figure 2). While considering burglary, again because of the higher frequency of inhabitants, Dhaka, Chattogram, and Khulna remain at the top, but the picture changes significantly when the rate is considered. Barisal, a new division, remains on the top alongside Dhaka division. At the same time, Sylhet division also appears at the same position as Chattogram and Khulna. Dhaka remains at the top along with Barisal (Figure 3). Rangpur, Rajshahi, and Mymensingh reported the lowest number of incidents of theft and dacoity in all cases.

Figure 2. Comparative total number of Theft and Rate of Theft (Theft_R) through all Divisions (Rate per million of the divisional population). Source: Developed by authors
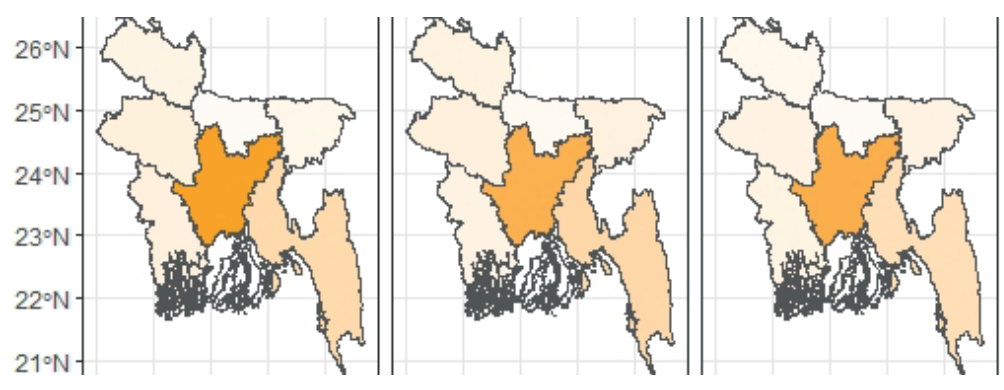

Theft

2500

2000

1500

1000

500 

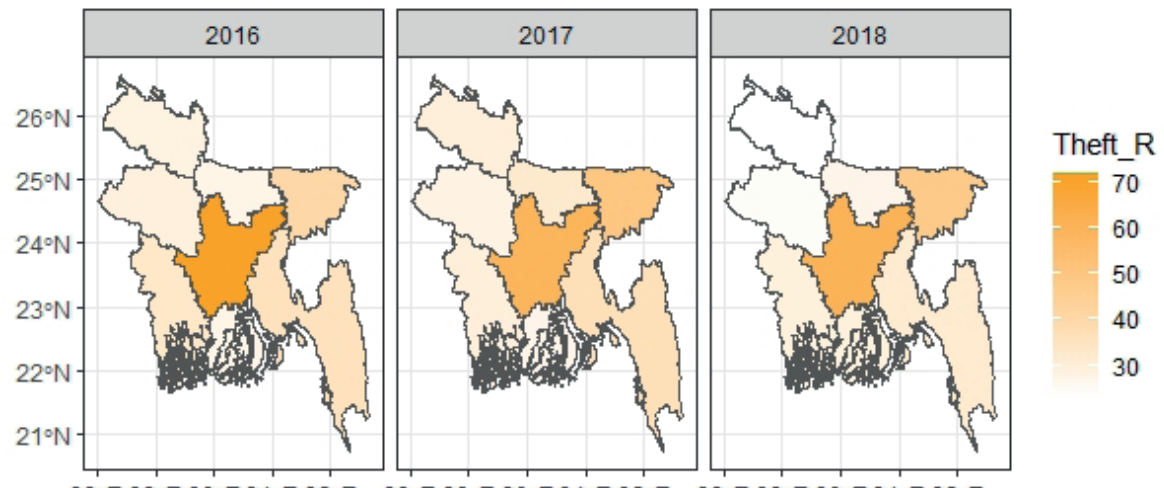

Figure 3. Comparative total number of Burglary and Rate of Burglary (Burglary_R) through All Divisions (Rate calculated per million of the divisional population) Source: Developed by authors
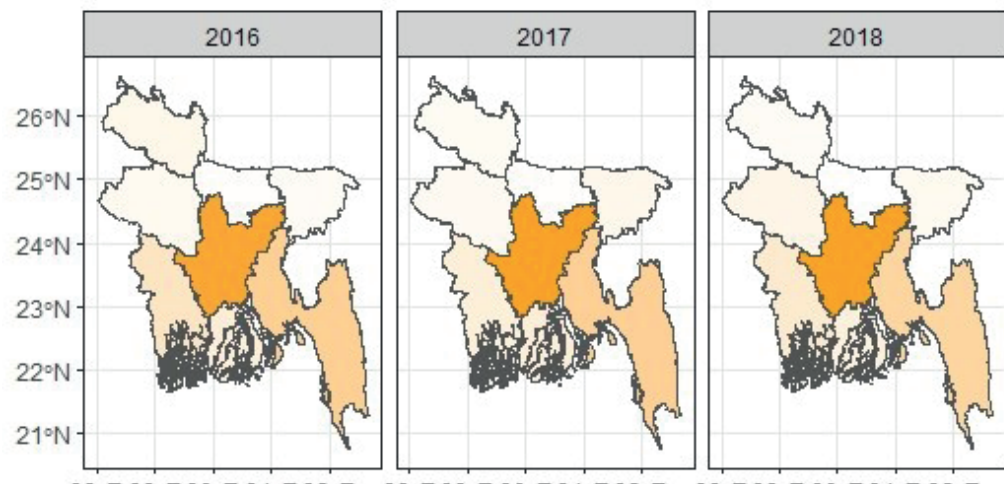

Burglary

$88^{\circ} \mathrm{E} 89^{\circ} \mathrm{E} 90^{\circ} \mathrm{E} 91^{\circ} \mathrm{E} 92^{\circ} \mathrm{E}$

$88^{\circ} \mathrm{E} 89^{\circ} \mathrm{E} 90^{\circ} \mathrm{E} 91^{\circ} \mathrm{E} 92^{\circ} \mathrm{E}$

$88^{\circ} \mathrm{E} 89^{\circ} \mathrm{E} 90^{\circ} \mathrm{E} 91^{\circ} \mathrm{E} 92^{\circ} \mathrm{E}$
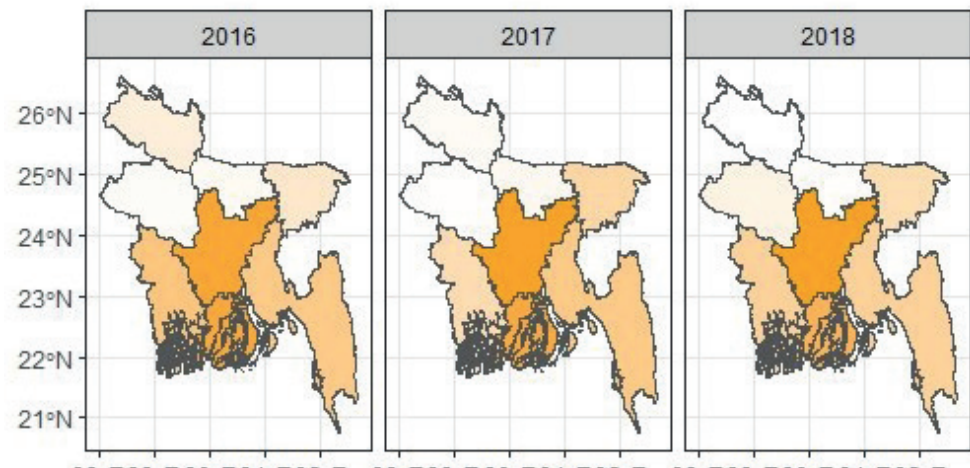

Burglary_R

25

20

15

10

750

500

250

$88^{\circ} \mathrm{E} 89^{\circ} \mathrm{E} 90^{\circ} \mathrm{E} 91^{\circ} \mathrm{E} 92^{\circ} \mathrm{E} \quad 88^{\circ} \mathrm{E} 89^{\circ} \mathrm{E} 90^{\circ} \mathrm{E} 91^{\circ} \mathrm{E} 92^{\circ} \mathrm{E}$

$88^{\circ} \mathrm{E} 89^{\circ} \mathrm{E} 90^{\circ} \mathrm{E} 91^{\circ} \mathrm{E} 92^{\circ} \mathrm{E}$ 


\section{Dacoity and Robbery}

Two other property-related crimes, which appear the most severe in Bangladesh, are dacoity and robbery (Figure 4, 5). Crime statistics from 2016 to 2018 and statistical thematic maps indicate that robbery and dacoity are moderately closer in frequency in all aspects. If we consider the total number of crimes, Dhaka remains at the top among all divisions. Chattogram, Sylhet, and Khulna remain in the highest rank (Figure 4). Again, the picture changes if the rate is calculated in all the divisions. Barisal and Sylhet remained at the top in 2016, but in the other two years, Dhaka and Sylhet displayed the highest rate of dacoity (Figure 4). Mymensingh remained less crimeprone in all aspects.

In the case of the total number of robberies, a new division appears in the picture. Like the previously discussed crimes, Dhaka and Chattogram remain at the top and Khulna, Rajshahi, and Sylhet remain at a moderate position. Mymensingh, as a small division, remains in a better position in terms of total crime. Again, if we consider the rate, most of the regions other than Mymensingh and Rangpur show quite a similar rate of criminality. Nonetheless, Mymensingh and Rangpur are evidentially safer for most of the years (Figure 5).

Figure 4. Comparative Distribution of Dacoity and the Rate of Dacoity (Dacoity_R) through all the Divisions (Rate calculated per million of the divisional population) Source: Developed by authors

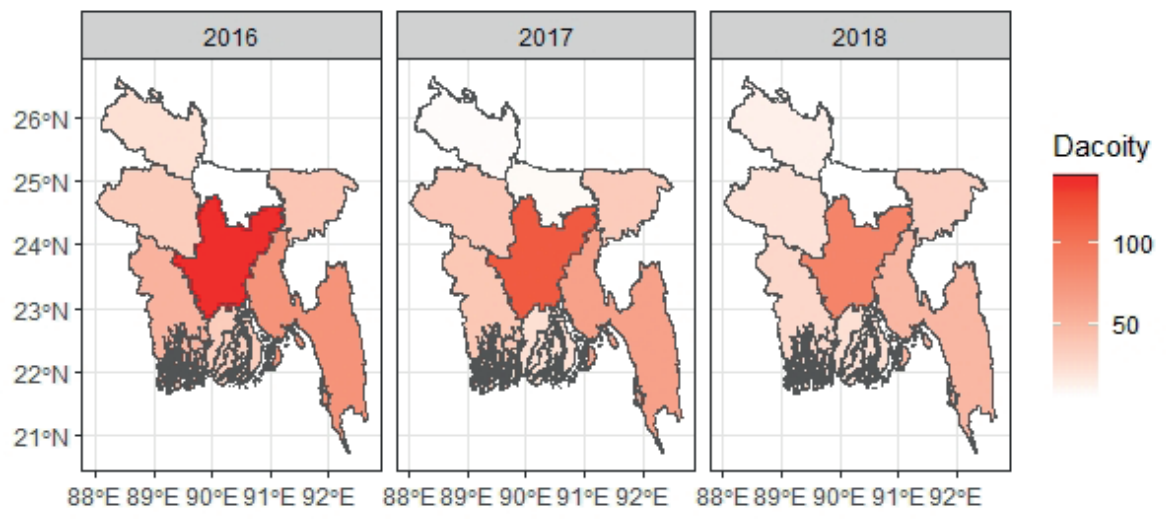



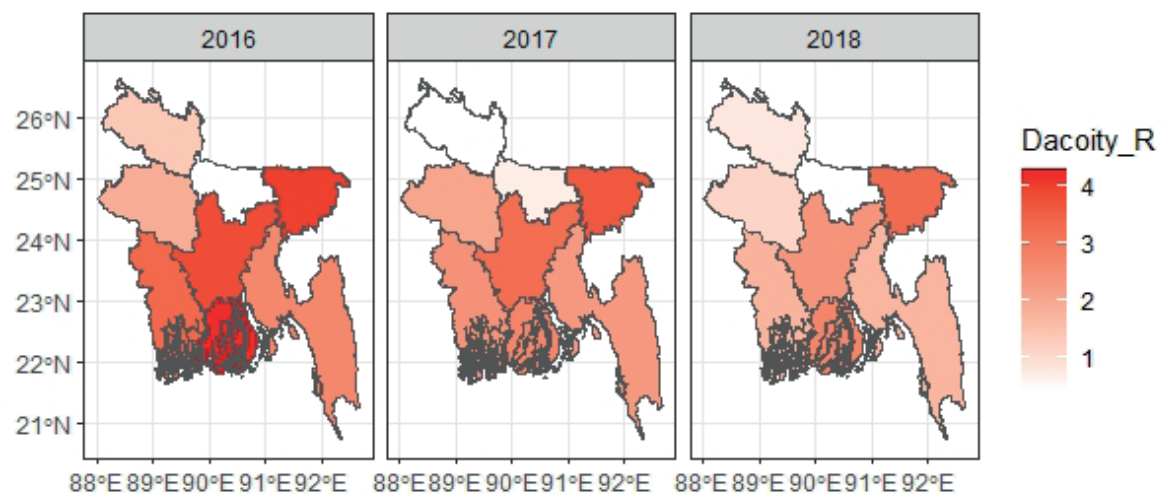

Figure 5. Comparative Distribution of Robbery and the Rate of Robbery (Dacoity_R) through all the Divisions (Rate calculated per 1 million of the divisional people) Source: Developed by authors
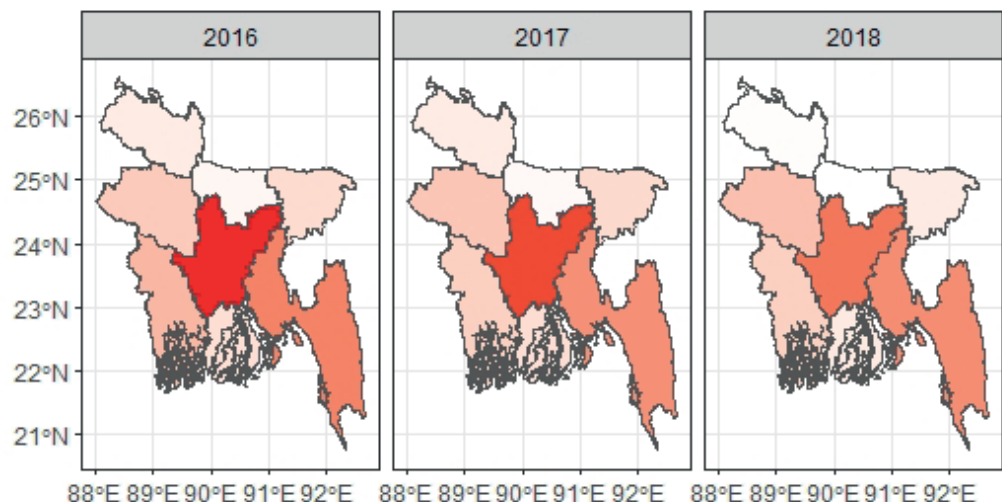

Robbery

$=250$

200

150

100

50
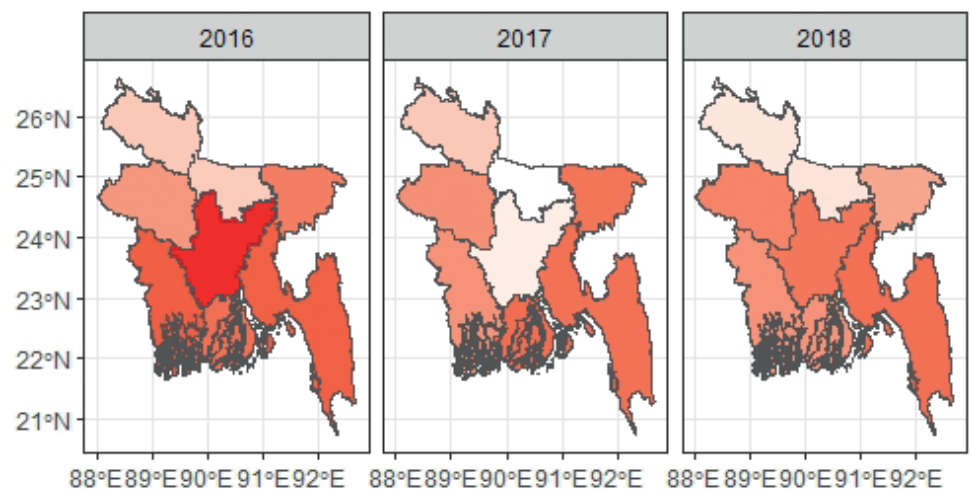

Robbery_R 


\section{Violent Offences of Bangladesh}

Violent crimes constitute those crimes which are connected to violence. The main purpose of these crimes is to harm people with physical injury and violence. Three recorded violent crimes were considered for this study. The maps indicate that the frequency of women and child repression in all the selected years is the highest. Murder is the second highest among these four selected violent crimes and holds a significant portion of the crimes. In terms of police assault, the frequencies are relatively lower, but these intensify public fear of losing their lives or are connected with a long-term impact on their lives. While this is comparatively low in frequency, the actual number of these crimes is not low. The relative frequency of these crimes over the period was child repression $>$ murder $>$ police assault. However, the discussion focusses on these violent crimes and their associated factors (Figure 6).

\section{Murder}

Murder is seemingly one of the most heinous crimes in the country. If we see the distribution of murder all over the country, Dhaka and Chattogram remain in the top position. Barisal, Mymensingh, Sylhet, and Rangpur displayed a relatively lower number of murders. Considering the rate among the divisions, Sylhet appeared the most vulnerable place at the top in 2017. Dhaka, Chattogram, and Khulna appear at a lower level. Rangpur is found to be a less vulnerable place (Figure 6 and Figure 7).

Figure 6. Comparative Distribution of Murder and the Rate of Murder (Murder_R) through all the Divisions (Rate calculated per million of the divisional population) Source: Developed by authors
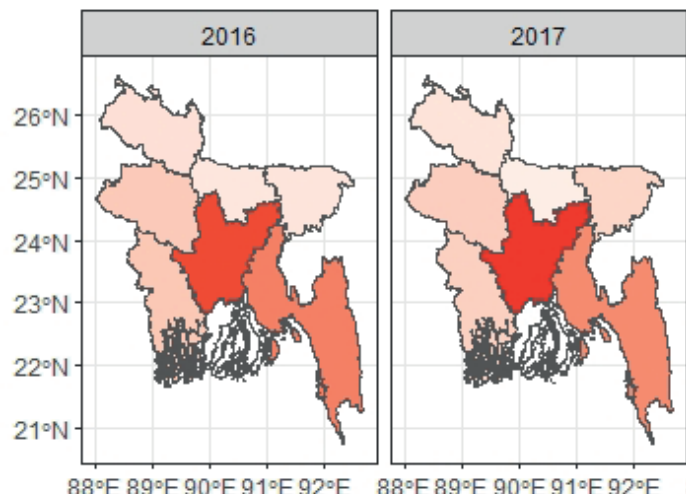

$88^{\circ} \mathrm{E} 89^{\circ} \mathrm{E} 90^{\circ} \mathrm{E} 91^{\circ} \mathrm{E} 92^{\circ} \mathrm{E}$

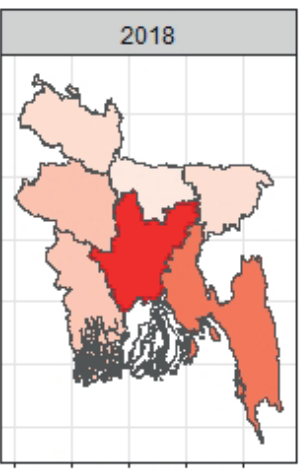

$88^{\circ} \mathrm{E} 89^{\circ} \mathrm{E} 90^{\circ} \mathrm{E} 91^{\circ} \mathrm{E} 92^{\circ} \mathrm{E}$
Murder 

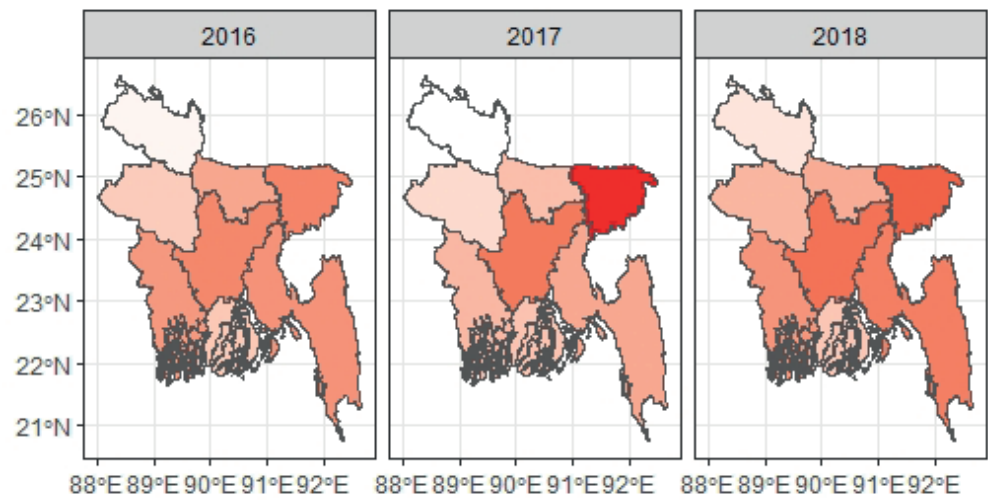

Murder_R

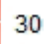

(1)

26

22

18

Figure 7. Rates of Murder in all Divisions (Rates calculated on per million of the divisional population) Source: Developed by authors

\section{Rates of Murders per 1 million}

\section{Rates Calulated on per million of the Divisional Population}

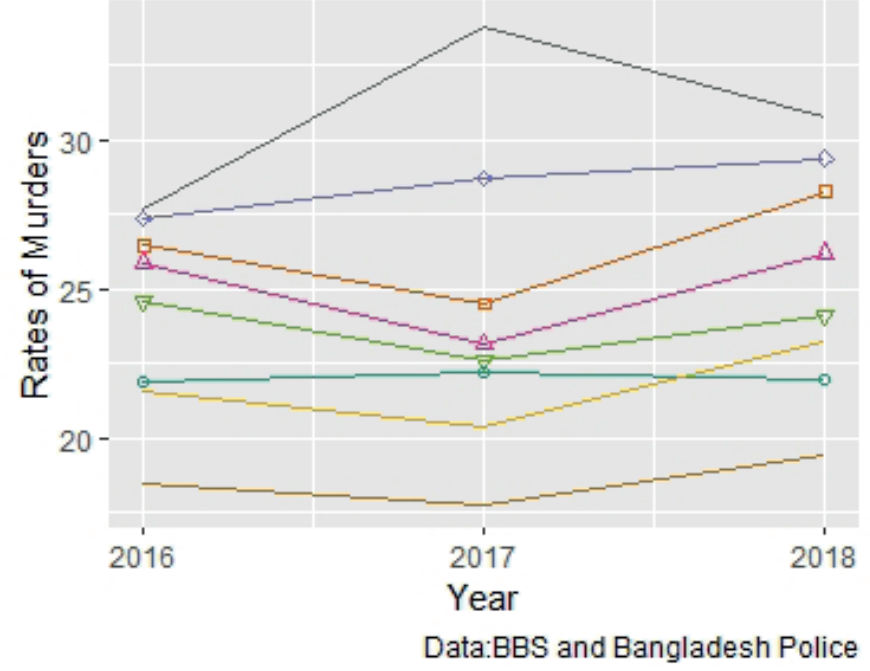

Zones

$\rightarrow$ Barisal

$\because$ Chattogram

$\rightarrow$ Dhaka

$\triangle$ Khulna

$\neg$ Mymensingh

- Rajshahi

- Rangpur

- Sylhet

\section{Women and Child Repression}

Women and child repression includes the most common forms of crimes (for example, abduction, rape, extortion, sexual assault ) which have occurred against women and children according to The Bangladesh Women \& Children Repression Prevention Act 2000 (Nari-O-Shishu Nirjaton Daman Ain). Women and child repression crimes are 
well distributed throughout the country rather than appearing only in the Dhaka division. Dhaka is still at the top considering the total number of crimes. While considering the rates, Barisal had the highest reported number of such incidents. Barisal, Dhaka, Khulna, and Rajshahi come next in the list of relative frequency considering the rate. Chattogram remains the less vulnerable among all the districts in terms of reporting such crimes (Figure 8 and 9).

Figure 8. Comparative Distribution of Women and Child Repression and the Rate of Women and Child Repression (Women_Child_Repression_R) through all the Divisions (Rate calculated per 1 million of the divisional people) Source: Developed by authors

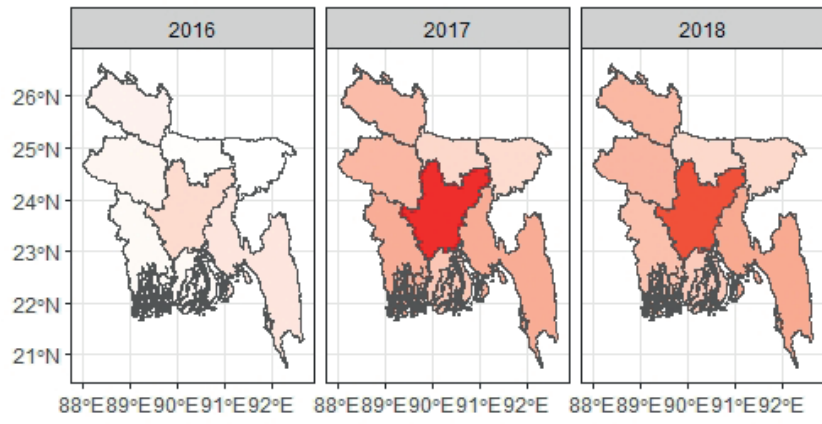

Woman_Child_Repression

$-5000$

4000

3000

2000

1000
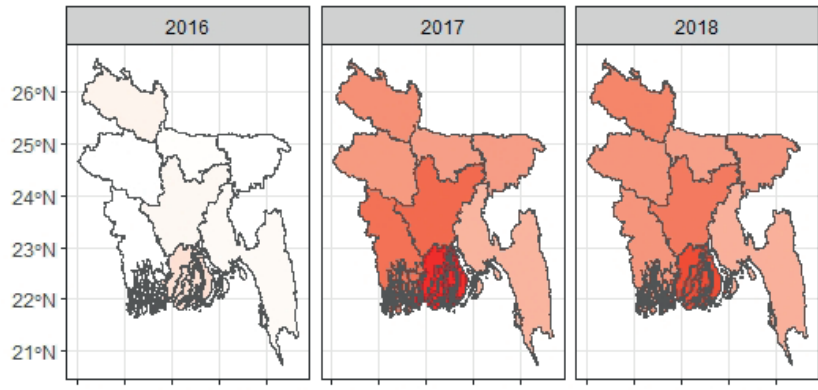

Woman_Child_Repression_R

150

100

50

$88^{\circ} \mathrm{E} 89^{\circ} \mathrm{E} 90^{\circ} \mathrm{E} 91^{\circ} \mathrm{E} 92^{\circ} \mathrm{E} \quad 88^{\circ} \mathrm{E} 89^{\circ} \mathrm{E} 90^{\circ} \mathrm{E} 91^{\circ} \mathrm{E} 92^{\circ} \mathrm{E} \quad 88^{\circ} \mathrm{E} 89^{\circ} \mathrm{E} 90^{\circ} \mathrm{E} 91^{\circ} \mathrm{E} 92^{\circ} \mathrm{E}$ 
Figure 9. Rates of Women and Child Repression in all Divisions (Rates calculated on per million of the divisional population) Source: Developed by authors

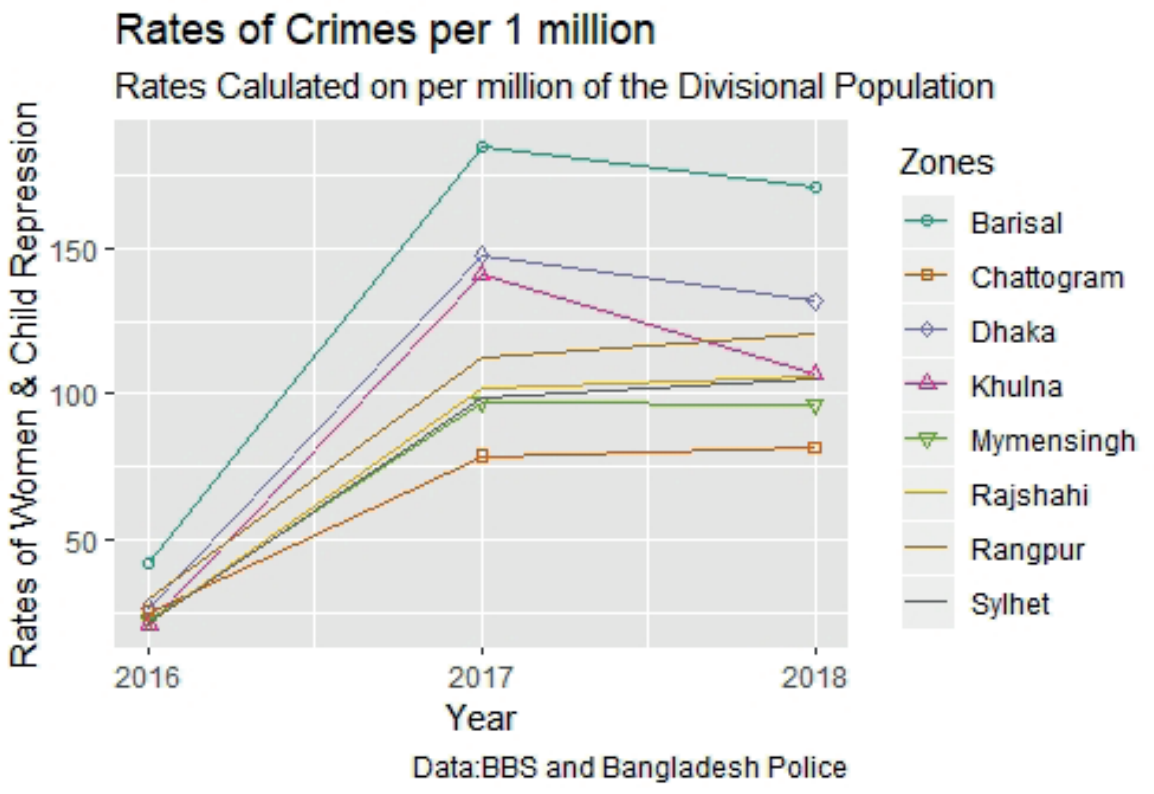

\section{Police Assault}

Considering the total number of police assaults, Dhaka and Chattogram usually remain at the top. In terms of the rates of this crime, Sylhet and Dhaka remain at the topmost position. However, statistics show that police assault is much higher in the western and central divisions of the country. Dhaka, Chattogram, and Sylhet had the highest crime rates in this regard (Figure 10). 
Figure 10. Comparative Distribution of Police Assault and the Rate of Police Assault (Police_Assault_R) through all the Divisions (Rate calculated per million of the divisional population) Source: Developed by authors
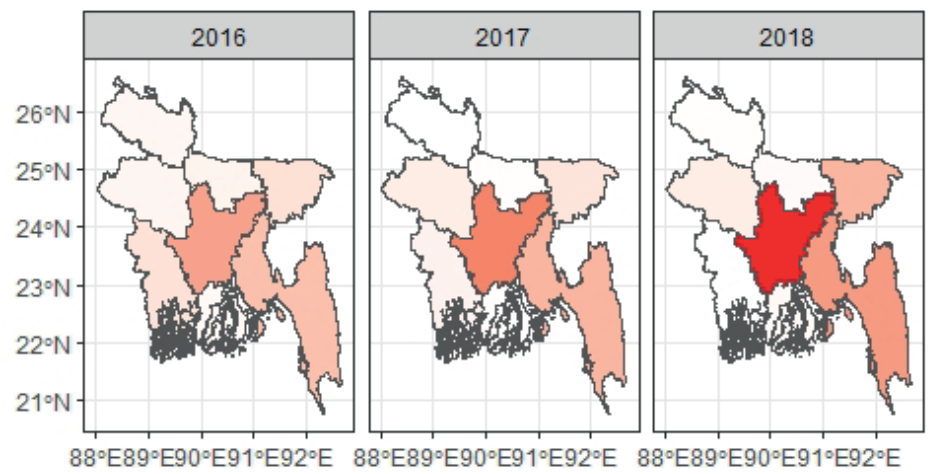

Police_Assault
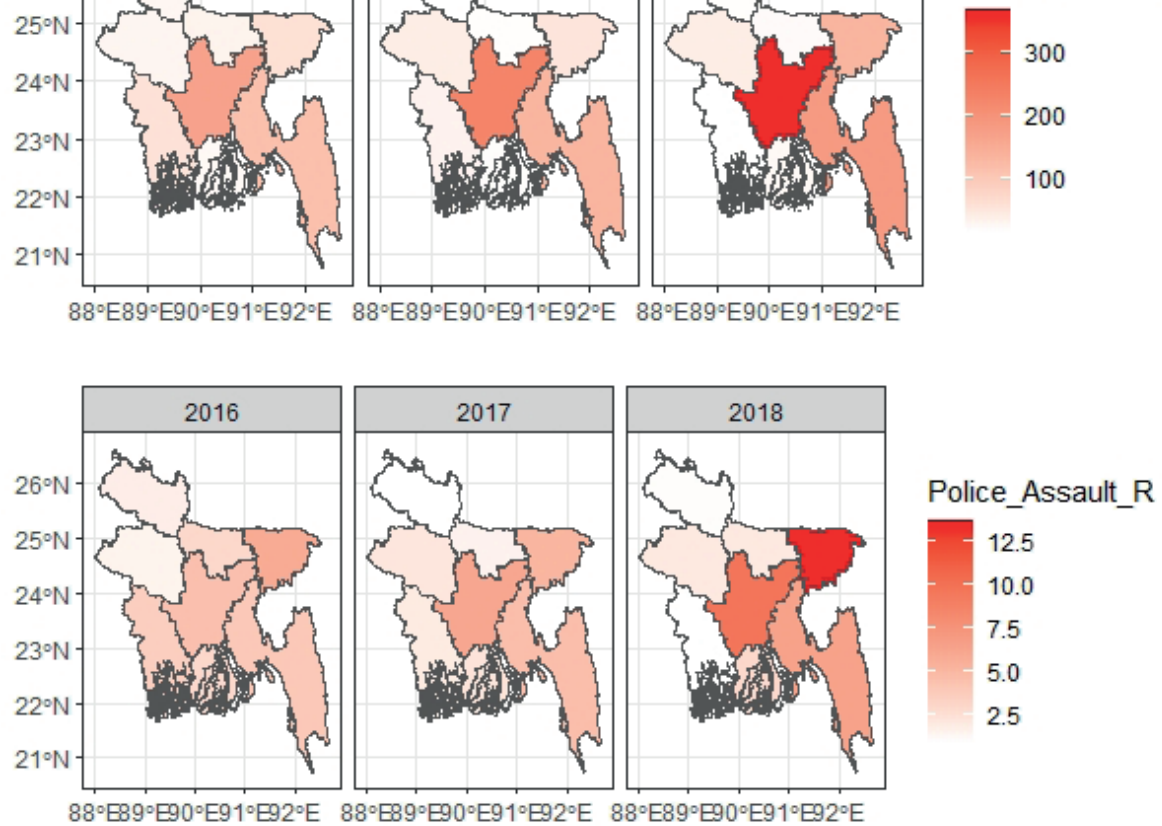

Police_Assault_R

$-12.5$

10.0

7.5

5.0

2.5

\section{Discussion}

\section{Patterns of geographic clustering}

This study has revealed some interesting findings of the crime patterns and geographic clustering of crimes in Bangladesh. Although geographic clustering of crimes in Bangladesh is difficult to predict other than having some spatial autocorrelation with different socio-economic or other factors of particular regions, as a pioneering study, the present one is a way forward in this aspect. This study posits that most of the crimes are clustered in two significant divisions, which are also more populous. It is logical to think that these areas are associated with different people and commuters who have their professional attachment to these places. The places where people frequently visit for their professional attachments are generally overcrowded and more preferable for 
probable offenders to commit crimes (Boivin, 2018). It is easy for offenders to hide in the crowd of people and evade law enforcement agencies' identification. In terms of population, Dhaka and Chattogram are the two largest divisions of the country. The first includes the capital of the country, and the second includes the commercial capital. Therefore, these two areas are densely populated. This has created a rational space for offenders to use as a host for the outworking of their crimes. It is evident that the central city areas overrepresent the data of these two divisions. Another important aspect is that many smaller divisions like Mymensingh, Barisal, and Sylhet have a comparatively smaller population size. The total number of crimes is found to be smaller there but may not be smaller in the real sense if the rates are calculated. It is very important to note that although Rajshahi and Khulna ranges are somewhat large, the total crimes in those areas are not high in most cases. While considering the rates of crimes in the divisions, we found a different portrayal of the crimes. For property crimes, Barisal and Sylhet were found to be more vulnerable. For murder, Sylhet was at the top.

This study indicates that areas with big cities (Dhaka and Chattogram) are more prone to harbouring more offenders than other areas. For murder, Sylhet was more vulnerable, but for women and child repression, Barisal was more vulnerable. For police assault, the western parts of Bangladesh, including Dhaka, Sylhet, Chattogram, were found to be the most vulnerable. As this study only intended to show the relative distribution of total crimes and crime rates based on divisions with limited available aggregate data, the generalizability of this research might be verified by other research at a subsequent time. It should be mentioned that there are various specific socio-economic and geographical aspects which may have vital impacts on the overall crime pattern (Wang et al., 2019). These factors can be identified in subsequent studies. However, at this initial stage of using GIS-based computerised crime mapping in Bangladesh, this research may have an important role in showing division wise crime distribution.

\section{Probable Causes of Geographic Clustering}

In the case of finding the causes of crime, understanding the physical and social environment is essential (Sim \& Miller, 2016). In many cases, crimes may have some geographic conditions (Chainey, 2014). In this regard, crime mapping can help the researchers to understand the influence of environmental conditioning on the frequency of crime. In the present study, the use of crime mapping to understand police recorded data can also be explained from the social data. Although these are not measured directly, these can be explained from the essential explanations of crimes. 
For property crimes, theft and burglary are seemingly high in all the regions. These crimes are connected to poverty and drug addiction. Additionally, drug related crime is 'a sensitive transnational issue' (Talukder, 2021, p.119). Many people in Bangladesh live under the poverty line, and their level of conscience and moral standard is not high. Due to extreme poverty and immense dishonest drive, many people of the lower socio-economic status in many cases may expose a tendency to involve themselves in crimes like theft and burglary. The same is true for dacoity and robbery. However, there are some causes behind the relatively higher number of cases of theft and burglary compared with those of dacoity and robbery. In the case of theft and burglary, the offenders intend to take away people's belongings without their knowledge. These crimes are often committed secretly where the risk of direct confrontation with victims is minimal. On the other hand, for the dacoity and robbery, the offenders need to confront the owners of the property where relative force is important, and this involves a high risk of apprehension. That is likely why offenders are more interested in getting property by taking only a minimal risk.

For violent crimes, women and child repression are found to be more frequent than police assault. In order to flee from violence (Talukder, 2015) and poverty these groups of people are often found to have become victims of trafficking (Talukder, Aktar and Bakul, 2015). In many cases, the patriarchal view of people influences their male counterparts to undermine women in the family structure. In modern Bangladesh women may work outside of the home, but still the attitude of society has not changed that much (Khan, 2015; Khan \& Kamruzzaman, 2010; Khan \& Shathi, 2018). As a result, conflicts are found more frequently in society. According to the rational choice theory, crimes happen when motivated offenders come into close contact with potential victims in the absence of any capable guardianship. Here, society creates men as motivated offenders to commit the offence in order to practise supremacy over women. In this context, other than law and moral education, there is no capable guardian to prevent it. That is why any family at any time can be a place of victim-offender interaction if certain conditions are met. Therefore, it is the highest recorded crime in all the studied divisions. For child abuse, the same explanations are applicable. They are exploited in different ways, namely, physically or psychologically. Sometimes they are assaulted within their family or outside their family. Murder, on the other hand, can be the ultimate result of all offences. Property crimes, family violence, political conflict, agitation, riot, and all other issues can turn into murder. As this is the severe result of all the conflicts, it is much more frequent in all areas of Bangladesh. In many 
cases, politically influential persons can twist the law to evade the allegation of murder. This is another important factor that facilitates a comparatively higher number of murder-related incidents. In the present context, law-enforcing agencies are also alleged to commit such offences in the name of "crossfire" or "gunfight". This also contributes to the homicide rate.

The crime of police assault features very low in police records. One probable reason behind this is that people tend to report less to the police about their misconduct. It may be triggered by their lack of confidence in the police regarding the complaints against their mates. Fear and mistrust for the police provoke people to think that they should not complain against the police. So, the figure may be underreported in the police record. Whatever the actual number of police assaults, people are always fearful of police action against civilians. Sometimes they are alleged to violate human rights severely.

Causes of geographic clustering of crimes have been proposed based on the literature and the prior knowledge of the researchers. These need to be verified in separate research studies by collecting empirical data on selected variables. This research only intended to portray the spatial distribution of crime in Bangladesh for the selected years and to propose some probable causes behind the distribution.

\section{Does Less in Number mean Less Serious?}

It is necessary to understand that less in total frequency does not indicate less severity in nature. Some crimes may be higher in number but not lethal in nature. People can recover from the ill impact of theft or burglary, but in cases like murder, police assault or serious violent crimes, the victims and their families suffer from long-term trauma. That is why, although sometimes violent crimes may be fewer in number, the total number of traumatised victims is very high. It is therefore essential to prevent these violent crimes with serious strategies and scientific management.

\section{Implications}

Public security issues, especially the possibility of criminality, are among the most pressing issues of the day. Scientific understanding of the spatial dimensions of crime is critical for containing and improving public security, particularly in large cities. The study of spatial distribution of crimes is essential, primarily in order to understand the required interventions and allocate resources by law enforcement officials according to necessity. Resource distribution should not be randomly administered but followed 
by a proper survey and time series analysis. This study may fulfil a need in the first instance. It may also help researchers to understand the preconditions that people consider while living or visiting any division. In this way, the ground for a regular cross-sectional and time series analysis may emerge in Bangladesh that can contribute to fighting crimes more successfully. Regular spatial analysis in different years and trend analysis may reduce the number of crimes by arranging different programs to prevent crimes from particular areas.

\section{Limitations}

The data used in this study were obtained from the official web sources of the Bangladesh Police (www.police.gov.bd/en/crime_statistic). These data were accumulated mainly by the police personnel based on their recorded crime information registered throughout the police investigation process. This number of crimes may underrepresent the actual figure of crime as all crimes are not properly reported to the police, and all reported crimes may not be recorded accordingly. Data collection was based on the broader definition of crimes such as murder, theft, dacoity, women and child repression, police assault, etc., where other associated issues were unknown. Therefore, data including the nature of crimes, number of victims, number of offenders involved, the exact location of the crime commission were not available. These broader definitions of different crimes were adopted from the penal law of Bangladesh and might be ambiguous to readers outside the country.

Additionally, the number of administrative divisions may not be equally comparable based on area, population density, and geopolitical nature. These locational characteristics may have an impact on the generalization of the analysis. However, a comparison was conducted for the purpose of this present analysis that might depict different pictures if these were considered according to other smaller-scale administrative regions. Another limitation of this study is that no validity check was possible for the data used in this study due to the lack of accessibility to the official raw data files stored in the repository of the Bangladesh Police.

\section{Contribution and Future work}

This research was an effort to understand some of the major crimes in Bangladesh based on their spatial distribution. As very few studies in Bangladesh have dealt with such problems on a bigger scale, this study can play a vital role in starting the journey of crime distribution and analysis based on mapping. Researchers in the following 
phases can take various factors into consideration to apply geographically weighted regression, OLS regression, and spatial autocorrelation better to establish the causation of crimes behind their geographical clustering.

\section{Conclusion}

Crime mapping is closely connected to effective crime prevention by ensuring predictive policing, especially for urban crime management (Jefferson, 2018; Rosser, Davies, Bowers, Johnson, \& Cheng, 2017; Townsley, 2017). This study is likely to be a new dimension of crime mapping in Bangladesh especially using GIS, GeoDa ${ }^{4}$ and $\mathrm{R}^{5}$. It is expected that the crime situation can be better understood in Bangladesh if these can be analysed according to the spatial patterns based on different geographic areas. This study is intended to trigger the identification of several demographic or other factors, which have long been unrecognised as underlying factors of criminality. A proper analysis of crime data itself can provide effective solutions for many long-lasting problems from different dimensions. Careful use of different levels of data with the georeferenced file can also give an idea about the allocation of resources based on the area coverage and locational details. With the use of proper scale, legend, borders, and neatlines can create high-resolution maps for the policymakers and common masses. However, insufficiency of data and inaccessibility to data can seriously influence such studies. Researchers should also be aware of the limitations of crime mapping (Jaishankar, Shanmugapriya, \& Balamurugan, 2004; J. Ratcliffe, 2010; J. H. Ratcliffe, 2002; Townsley, 2014). Despite the limitations and constraints, it is expected that this study has shown the geographic dimension of police-recorded crimes in Bangladesh. However, based on the findings of this study, the researchers recommend the following issues to improve law enforcement around the country and to reduce crimes.

Police officers should focus on the geographic clusters of specific crimes and take steps according to the crime statistics of specific regions.

For the preventive action of the police, this force should work with social institutions like educational institutions, religious institutions, and the family.

For reducing property-related crimes, environmental modelling is important. Installation of close circuit camera for vigilance, community policing and beat policing for specific communities may work in this regard.

For the prevention of dacoity and robbery, commuter control to the city area is important.

4 GeoDa is an open source software for processing and analyzing spatial data

$5 \mathrm{R}$ is a programming language and platform which allows users to manage different data and graphics 
For this, the government should take action to decentralise its business opportunities. The penal procedure of offenders should be strictly followed.

Police stations should be established at a rational distance to provide service to all of the citizens within the least possible time.

Proper recording of crime by georeferencing is important to map all the crimes and understand the probable locations of occurrence, probable way of perpetrators, displacement of crimes and hot spot analysis.

Peer-review: Externally peer-reviewed.

Author Contributions: Conception/Design of Study- M.B.U.K.; Data Acquisition- M.B.U.K.; Data Analysis/Interpretation- M.B.U.K., M.I.A.T.; Drafting Manuscript- M.B.U.K.; M.I.A.T.; Critical Revision of Manuscript- M.B.U.K., M.I.A.T.; Final Approval and Accountability- M.B.U.K., M.I.A.T.

Conflict of Interest: The author has no conflict of interest to declare.

Grant Support: The author declared that this study has received no financial support.

\section{References}

Amin, R., Nabors, N. S., Nelson, A. M., Saqlain, M., \& Kulldorff, M. (2015). Geographical Clusters of Rape in the United States: 2000-2012. Statistics and Public Policy, 2(1), 1-6. https://doi.org/10.1080/233044 3X.2015.1092899

Andresen, M. A., \& Malleson, N. (2015). Intra-week spatial-temporal patterns of crime. Crime Science, 4(1), 12. https://doi.org/10.1186/s40163-015-0024-7

Bangladesh Latitude and Longitude Map. (n.d.). Retrieved from https://www.mapsofworld.com/lat_long/ bangladesh-lat-long.html

Bernasco, W., \& Elffers, H. (2010). Statistical Analysis of Spatial Crime Data. In A. R. Piquero \& D. Weisburd (Eds.), Handbook of Quantitative Criminology (pp. 699-724). https://doi.org/10.1007/978-0-387-77650-7_33

Bohm, R. M., \& Haley, K. N. (2017). Introduction to criminal justice (Ninth Edition). Dubuque: McGraw-Hill Education.

Boivin, R. (2018). Routine activity, population(s) and crime: Spatial heterogeneity and conflicting Propositions about the neighborhood crime-population link. Applied Geography, 95, 79-87. https://doi.org/10.1016/j. apgeog.2018.04.016

Bowers, K., \& Johnson, S. D. (2014). Crime Mapping as a Tool for Security and Crime Prevention. In M. Gill (Ed.), The Handbook of Security (pp. 566-587). https://doi.org/10.1007/978-1-349-67284-4_25

Chainey, S. (2014). Crime Mapping. In G. Bruinsma \& D. Weisburd (Eds.), Encyclopedia of Criminology and Criminal Justice (pp. 699-709). https://doi.org/10.1007/978-1-4614-5690-2_317

Cracolici, M. F., \& Uberti, T. E. (2009). Geographical distribution of crime in Italian provinces: A spatial econometric analysis. Jahrbuch Für Regionalwissenschaft, 29(1), 1-28. https://doi.org/10.1007/s10037008-0031-1

Faruk, Md. Omar and Talukder, Md. Ishtiaq Ahmed, 2010, Urbanisation and Crime in Bangladesh: An Empirical Study on Dhaka City, South Asian Journal of Population and Health, vol.3, no.2.

Fitterer, J., Nelson, T. A., \& Nathoo, F. (2015). Predictive crime mapping. Police Practice and Research, 16(2), 


\section{1-135. https://doi.org/10.1080/15614263.2014.972618}

Gottschalk, P., \& Ørn, M. E. (2012). Crime mapping in police value shops: The Pocket Man case of child sexual abuse. Criminal Justice Studies, 25(1), 3-16. https://doi.org/10.1080/1478601X.2012.657899

Harkins, S. S., \& Reid, M. W. P. (2002). SQL: Access to SQL Server. https://doi.org/10.1007/978-1-4302-1573-8

Harries, K. D. (1999). Mapping crime: Principle and practice. Washington, DC (810 7th Street NW, Washington 20531): U.S. Dept. of Justice, Office of Justice Programs, National Institute of Justice, Crime Mapping Research Center.

Jaishankar, K., Shanmugapriya, S., \& Balamurugan, V. (2004). Crime Mapping in India: A GIS Implementation in Chennai City Policing. Annals of GIS, 10(1), 20-34. https://doi.org/10.1080/10824000409480651

Jefferson, B. J. (2018). Predictable Policing: Predictive Crime Mapping and Geographies of Policing and Race. Annals of the American Association of Geographers, 108(1), 1-16. https://doi.org/10.1080/24694452.2017 .1293500

Khan, M. B. U., Alam, M. A., \& Faruk, M. O. (2014). Modernisation and the Opportunity Factors of Crime: Dhaka City Experience. UITS Journal (UITS Research Centre), 3(2), 45-64.

Khan, Md. B. U., \& Kamruzzaman, M. (2010). The Present Vulnerability to Female Suicide and Homicide in Bangladesh: An Analysis of Recent Cases. Empowerment: A Journal of Women for Women, 17, 79-86.

Khan, Md. B. U., \& Shathi, I. J. (2018). Nature of Sexual Harassment Against the Female Students of Bangladesh: A Cross-Sectional Study in Tangail Municipality. International Journal of Social and Administrative Sciences, $3(2), 73-82$.

Kim, H., Chun, Y., \& Gould, C. A. (2013). Crime Scene Locations in Criminal Homicides: A Spatial Crime Analysis in a GIS Environment. In M. Leitner (Ed.), Crime Modeling and Mapping Using Geospatial Technologies (pp. 181-201). https://doi.org/10.1007/978-94-007-4997-9_8

Leclerc, B., Chiu, Y.-N., Cale, J., \& Cook, A. (2016). Sexual Violence Against Women Through the Lens of Environmental Criminology: Toward the Accumulation of Evidence-based Knowledge and Crime Prevention. European Journal on Criminal Policy and Research, 22(4), 593-617. https://doi.org/10.1007/s10610-015-9300-z

Leitner, M. (Ed.). (2013). Crime Modeling and Mapping Using Geospatial Technologies. https://doi.org/10.1007/97894-007-4997-9

Leong, K., \& Chan, S. C. F. (2013). A content analysis of web-based crime mapping in the world's top 100 highest GDP cities. Crime Prevention and Community Safety, 15(1), 1-22. https://doi.org/10.1057/cpcs.2012.11

Maltz, M. D., Gordon, A. C., \& Friedman, W. (1991). Mapping Crime in Its Community Setting. https://doi. org/10.1007/978-1-4612-3042-7

Moncada, E. (2010). Counting bodies: Crime mapping, policing and race in Colombia. Ethnic and Racial Studies, 33(4), 696-716. https://doi.org/10.1080/01419870903380854

Pope, M., \& Song, W. (2015). Spatial Relationship and Colocation of Crimes in Jefferson County, Kentucky. Papers in Applied Geography, 1(3), 243-250. https://doi.org/10.1080/23754931.2015.1014275

Population, total—Bangladesh. (n.d.). Retrieved November 12, 2019, from https://data.worldbank.org/indicator/ SP.POP.TOTL?locations $=\mathrm{BD}$

Ratcliffe, J. (2010). Crime Mapping: Spatial and Temporal Challenges. In A. R. Piquero \& D. Weisburd (Eds.), Handbook of Quantitative Criminology (pp. 5-24). https://doi.org/10.1007/978-0-387-77650-7_2

Ratcliffe, J. H. (2002). Damned If You Don't, Damned If You Do: Crime Mapping and its Implications in the Real World. Policing and Society, 12(3), 211-225. https://doi.org/10.1080/10439460290018463

Rosser, G., Davies, T., Bowers, K. J., Johnson, S. D., \& Cheng, T. (2017). Predictive Crime Mapping: Arbitrary Grids or Street Networks? Journal of Quantitative Criminology, 33(3), 569-594. https://doi.org/10.1007/ s10940-016-9321-x

Saadi, M.A, Rahman, M.A and Talukder, M.I.A, (2008), "SocioSpatial Aspects of Crime in Dhaka City" Journal of Socioeconomic Research and Development (JSER), Volume: 5, Issue: 6. 
Shekhar, S., Xiong, H., \& Zhou, X. (Eds.). (2017). Encyclopedia of GIS. https://doi.org/10.1007/978-3-319$17885-1$

Sim, S., \& Miller, A. (2016). Exploratory Spatial Data Analysis of the Distribution of Multiple Crimes: A Case Study of Three Coastal Cities. Papers in Applied Geography, 2(1), 79-84. https://doi.org/10.1080/237549 31.2015.1014277

Talukder, Md. Ishtiaq Ahmed, (2021). Transnational Organized Crime and Security Threats in the Context of Bangladesh, Journal of Social Sciences and Humanities, Vol. 07, No. 02, pp.114-122.

Talukder, Md. Ishtiaq Ahmed, (2015). The Prevalence of Domestic Violence against Women: An Analysis on Women Victim of Tangail District, South Asian Journal of Population and Health, Volume-8, Number 1 \&2, ISSN:1560-4373

Talukder, Md. Ishtiaq Ahmed, Aktar, Mahmuda, and Bakul, Shirin, (2015). Nature and Extent of Children and Women Trafficking in Bangladesh: A Descriptive Analysis, Chhattisgarh Law Journal. ISSN 2394-5281.Vol I. Issue II.

Tang, Y., \& Khan, Md. B. U. (2018). Internal Law Enforcement Challenges in Bangladesh: An Analysis. Humanities and Social Sciences Letters, 6(3), 06-120.

Townsley, M. (2014). Inferential Crime Mapping. In G. Bruinsma \& D. Weisburd (Eds.), Encyclopedia of Criminology and Criminal Justice (pp. 2470-2479). https://doi.org/10.1007/978-1-4614-5690-2 318

Townsley, M. (2017). Crime Mapping and Spatial Analysis. In B. LeClerc \& E. U. Savona (Eds.), Crime Prevention in the 21st Century (pp. 101-112). https://doi.org/10.1007/978-3-319-27793-6_8

Wang, L., Lee, G., \& Williams, I. (2019). The Spatial and Social Patterning of Property and Violent Crime in Toronto Neighbourhoods: A Spatial-Quantitative Approach. ISPRS International Journal of Geo-Information, 8(1), 51. https://doi.org/10.3390/ijgi8010051

Wolff, M., \& Asche, H. (2009). Geovisualization Approaches for Spatio-temporal Crime Scene Analysis - Towards 4D Crime Mapping. In Z. J. M. H. Geradts, K. Y. Franke, \& C. J. Veenman (Eds.), Computational Forensics (Vol. 5718, pp. 78-89). https://doi.org/10.1007/978-3-642-03521-0_8

Xiong, H. (2016). Urban Spatial Disorganization and Crime: Punctate Distribution Pattern. In H. Xiong, Urban Crime and Social Disorganization in China (pp. 71-93). https://doi.org/10.1007/978-981-287-859-5_4

Zhang, H., \& Song, W. (2014). Addressing issues of spatial spillover effects and non-stationarity in analysis of residential burglary crime. GeoJournal, 79(1), 89-102. https://doi.org/10.1007/s10708-013-9481-2 
